ISSN 1518-3483

Licenciado sob uma Licença Creative Commons

\title{
Formação de professores, complexidade e trabalho docente
}

\section{Teacher education, complexity and teaching work}

\author{
La formación del profesorado, la complejidad \\ y el trabajo docente
}

\section{Bernardete Angelina Gatti*}

Fundação Carlos Chagas, São Paulo, SP, Brasil

\section{Resumo}

As condições societárias, hoje, mostram-se multifacetadas e heterogêneas, e, por isso, mais complexas. Pensar e fazer a formação de professores envolve considerar condições situacionais e conscientizar-se das finalidades dessa formação, considerar os porquês, o para quê e o para quem ela é realizada, assumindo compromissos éticos e sociais. Levando em conta isso, o artigo propõe inicialmente visitar o cenário que se nos apresenta hoje na sociedade em geral, e, na educação no Brasil como ponto de partida para uma reflexão sobre como se realiza essa formação e seus efeitos fundamentando a necessidade de mudanças radicais nesse processo formativo.

Palavras-chave: Sociedade complexa. Formação de professores. Ação docente. Educação escolar.

\footnotetext{
BAG: Doutora, e-mail: gatti@fcc.org.br
} 


\section{Abstract}

Society today is a complex matter because social situations are a multifaceted phenomenon. Education is an action made in a society and so we may consider the scenery where she is realized. Teachers education may be developed in attention of the settings in which they are realized, taking in account questions of ethics and social compromises. So, in this article propose to bring data of the educational situation in Brazil and the way we form teachers and point problems that researches point out.

Keywords: Complex society. Teachers education. Education works. School education.

\section{Resumen}

Este artículo reflexiona sobre la situación de la educación en Brazil y la situación de la formación de docentes para la educación básica, com base en resultados de investigaciones. Considera la complexidad de la sociedad hoy e la necessidad de compromisos éticos y sociales en esta formación. Pensar y hacer formación de docentes necessita considerar el escenario social atual e definir porque hacer ésta formación.

Palabras clave: Sociedad complexa. Formación de docentes. Professores. Educación en la escuela.

\section{Introdução}

Pensar e fazer a formação de professores envolve considerar condições situacionais e conscientizar-se das finalidades dessa formação, considerar os porquês, o para quê e o para quem é realizada essa formação, assumindo compromissos éticos e sociais. Considerando isso, propomos inicialmente visitar o cenário que se nos apresenta hoje em nossa sociedade, onde essa formação e o trabalho dos professores se insere.

Redes educacionais e escolas são instituições integrantes da sociedade e, como tal, nelas se encontram os mesmos traços característicos das dinâmicas sociais, aí incluídas tensões e conflitos de uma dada conjuntura. Vivemos um cenário social cambiante, onde competitividade e 
individualismos são traços característicos, em que sentimentos de realização ou de injustiça se constroem, em condições de multiculturalismo, de novas linguagens e da emergência de demandas por justiça social e equidade educacional. Nesta ambiência o trabalho dos professores e gestores educacionais se efetiva, a aprendizagem dos alunos se constrói. Compreender essas condições e seus impactos na educação escolar tornase uma necessidade para quem busca caminhar na direção de superação de impasses educacionais e impasses sobrevenientes no campo do trabalho docente. Dilemas se levantam quanto às formas de compreensão do momento contemporâneo, sobre condições de exercício da democracia, sobre valores, diversidades e sentidos do agir humano, do agir educacional, do trabalho nas redes escolares. Vivemos tensões nas propostas e concretizações da formação inicial de professores, não só no Brasil como em muitos outros países. Aqui vivenciamos padrões culturais formativos arraigados, estruturados em nossa história educacional desde os inícios do século XX, padrões que se mostram em conflito com o surgimento de novas demandas para o trabalho educacional, as quais se colocam em função de contextos sociais e culturais diversificados, após cem anos de trajetória histórico-social e cultural. Trajetória essa afetada, em particular, pelo desenvolvimento de novas formas de comunicação e das tecnologias como seu suporte, e, novas formas de trabalho e de relações produtivas.

No entrecruzamento complexo dessas condições é que questionamentos quanto à formação de professores para a educação básica se colocam: sobre sua relação com as necessidades sociais e educacionais das novas gerações, sua relação com perspectivas político-filosóficas quanto ao papel da educação escolar, sobre suas relações e contribuições com visões de futuro, e, mesmo, sobre suas relações com os conhecimentos a serem tratados nesse nível de educação. Dúvidas surgem sobre como formar esses docentes, quais são as bases institucionais e curriculares mais condizentes com os desafios que as novas gerações estão a colocar, que os novos conhecimentos colocam, que novas e conflitantes relações no social se mostram desafiando nossas compreensões. 


\section{Aspectos de contexto: complexidades}

Temos problematizações quanto aos caminhos trilhados historicamente, tanto no mundo social como no mundo das ciências e nos processos educacionais, e há procura de alternativas para compreender situações, para as convivências, para o pesquisar e o explicar, para o ensinar. Instalam-se buscas por novas formas de compreensão de fatos, ocorrências e realidades, tanto quanto ao mundo natural como quanto ao mundo social. Se de um lado temos um cenário social que aponta para uma configuração cibernético-comunicacional como base das relações sociais e de trabalho, de outro temos o cenário de populações desprovidas, excluídas desse cenário. Nas ciências, há rupturas em modelos epistemológicos, induzidas pelas ideias de indeterminação, instabilidade, descontinuidade. O pluralismo teórico mostra-se rompendo com as pretensões de uma cultura e uma ciência universal e hegemônica. Há abandono de determinismos de diferentes inspirações e há o surgimento de novas visões sobre os movimentos da natureza e sua constituição e mudanças. Novas perspectivas do humano-social enfocam as diferenciações, construindose conhecimentos e saberes que destacam as heterogeneidades culturais, e não as unicidades e homogeneidades, estas consideradas como fatores de obscurecimento quanto à compreensão da condição humana, seja ela social, educacional ou cultural.

Marca presença a questão da diversidade de costumes, de religião, de concepções de vida, gosto musical, ritos, com a circulação das pessoas intensificada a partir de diversas territorialidades. Surgem neste movimento, as diferenças, que passam a ser reconhecidas e consideradas. A luta pela manutenção de identidades étnico-culturais, das minorias diversas, por um espaço social, pelo reconhecimento e respeito às diferenças, a luta pelo meio ambiente, são fenômenos recentes na história humana. São expressões da diversidade biológica, social, cultural, para sua própria preservação. São expressões que se contrapõem às padronizações, aos olhares monolíticos que colocam tudo sob uma única ótica excludente dos demais. Nas ciências, as interdependências entre campos aparecem 
cada vez mais necessárias ao aprofundamento e avanço das compreensões sobre a natureza, o mundo, o universo, a sociedade humana. Teorias conflitantes, ou em contraponto, se colocam. Dialeticamente esses movimentos no social e nas ciências, que se imbricam nos movimentos das culturas, vão construindo alguns consensos e perspectivas, que se sustentam por um tempo, mostrando-se como sínteses que podem fazer avançar nosso processo civilizatório. Mas as antíteses logo se revelam nesse universo informático-virtual onde se movem conceitos diversificados. Toda a complexidade do universo e das comunidades humanas se revela nesse cenário.

As compreensões e teorizações construídas sobre o universo educacional, que se consolidaram em grande parte nos séculos dezenove e vinte, ante a materialidade dos fatos e os movimentos históricos contemporâneos, passam a ser questionados, lançando-se um olhar crítico sobre a legitimidade de certas proposições, formações, interpretações, repetidas e reificadas como imutáveis ou como compreensões universais. Esses questionamentos aparecem no debate científico e social já nas últimas duas décadas do século passado e intensificam-se nestes últimos anos. Dúvidas e procuras guiam novos estudos e ações, ainda que sejam ações localizadas e restritas em sua abrangência. Uma questão que entra em pauta é a das interdisciplinaridades e das formações interdisciplinares, das compreensões que mostram intersecções e transvariações em situações e fatos, chocando-se com um universo formativo em que predomina nos currículos a fragmentação disciplinar de olhar unívoco e a fragmentação dos tempos formativos, estruturados a partir do século dezessete, que atingiram seu apogeu no século dezenove, e que têm vigência na escolarização até os nossos dias. Nesta conjuntura, a formação de professores nas licenciaturas, hoje, mostra-se justamente em choque direto com as demandas do trabalho escolar a ser realizado na educação básica, com o trabalho educacional e escolar com e para as novas gerações que sucessivamente adentram nas salas de aula. Com uma estrutura formativa reificada nas proposições consolidadas entre nós, mais formalmente, nos inícios do século vinte, sem integrar a visão de que esses cursos objetivam 
formar profissionais para a educação escolar com as novas gerações, as licenciaturas se mostram em suas dinâmicas formativas alienadas das realidades socioculturais contemporâneas, da complexidade que transita do social para os espaços das escolas e das salas de aula, e das demandas que se colocam ao trabalho de um professor na interface com seus alunos no dia a dia das redes escolares.

\section{Novas perspectivas e consciência crítica}

Uma nova visão é necessária na seara educacional, como também a construção de uma consciência mais crítica quanto a nossas ações formativas no campo da docência. As comunidades humanas se tornaram mais heterogêneas, há grande densidade demográfica no mundo de hoje, há intensificação das comunicações globais evidenciando a pluralidade de conceitos e problemas, bem como, pondo em aberto a questão dos enormes desafios que se levantam quanto à preservação da vida neste planeta. A educação escolar tem um papel essencial nessa direção, e os professores são chamados a comprometerem-se com um ensino que propicie aprendizagens as quais permitam às crianças e jovens, como cidadãos, tomarem decisões fundadas em conhecimentos sólidos e agirem pela preservação de condições específicas ligadas não só ao nosso habitat natural, mas também em alto grau, ligadas às comunidades humanas e suas ações e às suas próprias vidas. Coloca-se como um direito da cidadania a socialização e apreensão dos conhecimentos que podem contribuir para a vida cidadã com dignidade, e, nesse processo a Educação, considerada em seus diferentes ângulos e formatos, é central, torna-se área de interesse público vital e a Educação Escolar assume aí papel relevante, e nela, destaca-se o trabalho dos professores.

O contexto atual descrito em rápidos traços acima, em que mudanças socioculturais interseccionadas se processam, em que as redes escolares recebem uma diversidade de segmentos sociais com expressões culturais próprias, em territórios com características complexas pelos vários fatores aí intervenientes, esse contexto se entretece com os 
ambientes escolares e o trabalho educacional. É atuante nas relações que se estabelecem dentro das escolas, nas relações com as comunidades de interface, na atribuição de significados aos conhecimentos e às aprendizagens, gerando ruídos, incompreensões, desencontros, dificuldades diversas, linguagens e formas de comunicação que não encontram eco. As situações geradas no ambiente escolar, e aí vividas, pedem novas compreensões para orientação de ações e relações interpessoais e educativas (professores-alunos-pais; professores-professores; professores-gestores; funcionários-alunos; gestores-alunos-pais, etc.), e, sobretudo, novas posturas didáticas e formas diversificadas nas relações pedagógicas. Novas situações, novas respostas. Caso contrário tem-se pouca ressonância, ou dissonâncias, pouca efetividade pedagógica, impasses.

Entra em pauta a questão da profissionalidade docente. A docência como profissão contempla a atribuição de executar um trabalho específico, com uma base de conhecimentos teóricos e práticos apropriada, a capacidade de utilizar esses conhecimentos em situações relevantes e a capacidade de recriar, por reflexão constante a partir da prática, seus saberes e fazeres. (Avalos, 2013; Roldão, 2007; Ramalho, Nuñez e Gauthier, 2003). Qual formação responderia às demandas socioeducacionais no cenário atual? Qual a relação: profissionalidade X profissionalização.

Desse modo, refletir sobre a formação necessária para os professores nas condições histórico-culturais que se apresentam hoje não é questão de senso comum apenas, nem de vagas opiniões. Refletir e ponderar sobre as implicações do trabalho pedagógico nas escolas mostra-se com relevância ímpar, e demanda considerar a complexidade do trabalho docente na contemporaneidade. Porém, se visamos pensar em mudar o cenário da formação de professores que hoje nos é apresentado, precisamos ir além. Faz-se necessário olhar sem véus a situação presente, o que se está fazendo e os efeitos histórico-sociais dessas ações. Neste esforço, as pesquisas sobre a realidade escolar brasileira e a realidade da formação de professores nos cursos superiores nos ajudam. 


\section{Pesquisas e seus dados}

Esforços têm sido desenvolvidos nos vários níveis da gestão educacional - federal, estadual e municipal — em prol da ampliação do atendimento e da qualificação educativa nas redes de ensino. Observouse um incremento nos investimentos públicos em educação nos últimos vinte anos, com alguns ganhos importantes, como o atendimento quase universal na primeira etapa do ensino fundamental, a redução da evasão e da defasagem idade-série, ampliação do atendimento na pré-escola e nas matrículas no ensino médio e no profissional. No entanto, ainda se mostram graves problemas na trajetória escolar das crianças e jovens que se constituem em enormes desafios às políticas da educação em seus efeitos. Ficamos a dever em questões de qualidade e inclusão educacional. Callegari (2015), analisando dados da Avaliação Nacional de Alfabetização (ANA), que abrangeu 55.000 escolas públicas e 2,6 milhões de alunos do $3^{\circ}$ ano do ensino fundamental, nos mostra que: no $3^{\circ}$ ano do ensino fundamental uma em cada quatro dessas crianças não sabe ler ou fazer operações aritméticas simples, e, $45 \%$ delas não sabe escrever corretamente um texto simples. Esse autor pondera, então, que "aos oito anos de idade essas crianças já estão em situação que determina precocemente que terão sérias dificuldades na sua trajetória educacional e de vida, e essa situação é raiz para a desigualdade social e a exclusão" (p. 2). Ou seja, temos graves problemas no processo de alfabetização das crianças e essa condição é fator de não favorecimento à meta de equidade social que as políticas colocam com tanta veemência em seus documentos e discursos. Processamentos dos microdados dos Censos Escolares e do SAEB (Sistema de Avaliação da Educação Básica) mostram que a trajetória escolar dos alunos tem ainda perdas significativas: a proporção da população de 12 anos de idade, no Brasil, com ao menos os cinco anos iniciais do Ensino Fundamental concluídos é de apenas $62 \%$, com variações regionais grandes. Exemplificando: São Paulo (80\%), Distrito Federal (79\%), Minas Gerais (69\%); Rio de Janeiro (56\%); Pernambuco (52\%); Alagoas (42\%). A média de escolaridade dos brasileiros é de 7,7 anos, menos do que a 
duração do ensino fundamental. Além disso, os alunos que permanecem nas redes escolares mostram um desempenho nas provas nacionais que evidencia um retrato muito problemático. Encontra-se que a porcentagem de alunos que aprenderam o que seria adequado, ao final de cada etapa de educação em Língua Portuguesa, no $5^{\circ}$ do Ensino Fundamental, é de apenas $45 \%$, no $9^{\circ}$ ano, apenas $29 \%$, e no $3^{\circ}$ ano do Ensino Médio, somente 27\%; em Matemática, no $5^{\circ}$ do Ensino Fundamental apenas $40 \%$ atinge o nível adequado, no $9^{\circ}$ ano, apenas $16 \%$, e, no $3^{\circ}$ ano do Ensino Médio, só 9\% deles está nesse nível (Todos pela Educação, 2015).

Quanto às Licenciaturas, se o total de matrículas nos cursos presenciais e a distância vem mostrando um volume grande de matriculados (nos últimos três anos em torno de um milhão e trezentos mil matriculados, sendo $57 \%$ em instituições privadas), o número de concluintes fica em torno de duzentos mil/ano, 33\% em instituições públicas e $67 \%$ nas privadas. Análise histórica de dados de ingressantes que se tornam concluintes nesses cursos mostra um índice estimativo de $43 \%$ de conclusões em relação aos ingressantes a cada ano (INEP, 2009; 2010; 2011; 2013). De acordo com a literatura analítica do quadro curricular das licenciaturas, há problemas recorrentes que se evidenciam quanto à qualidade dessa oferta: redução curricular e de horas de formação; currículo com pouca vocação para formar profissionais docentes; expansão geométrica das licenciaturas no formato à distância em condições pouco qualificadas; formação dos docentes das próprias instituições de ensino superior para o trabalho de formação de professores para a Educação Básica (as pósgraduações não favorecem formações em didática, metodologias e práticas de ensino). O estudo das ementas dos cursos mostra bem esses e outros problemas formativos (Gatti, 2014; Gatti, Barretto e André, 2011; Monfredini, Maximiano e Lotfi, 2013). Exemplificando a pouca formação nas áreas de preparo profissional para o exercício da docência, oferecidas no ensino superior, nesses cursos, estudo de Gatti et al. (2012) mostra que, em média, nos cursos de licenciatura em Biologia somente $5 \%$ do tempo é dedicado a essa formação específica, em História, $8 \%$, em Letras-Língua Portuguesa, 7\%, em Matemática, 11\%, em Pedagogia, 8\%. 
Predominam nelas os conhecimentos de área e a formação para a educação mostra-se genérica e incompleta, contribuindo pouco para a construção de profissionalidades docentes. A formação para atuar em creches e pré-escolas deixa muito a desejar, e, assim, compreende-se a volta crescente em muitos estados da oferta em nível médio, normal, para formar esses professores (MEC/INEP/DEED, 2012). Com esse crescimento e a demanda de gestores, foi realizada alteração na LDB (BRASIL, 1996), propondo a formação em nível médio de professores para a educação infantil em forma perene pela Lei 12.796/2013 (BRASIL, 2013).

Quanto aos professores atuantes nas redes públicas, estudo de Alves e Silva (2013) nos mostra dados sobre a proporção de professores dos anos finais do ensino fundamental e médio das escolas públicas que têm formação na área de atuação, conforme prescrito nas normas. Esse estudo mostra que, dos que lecionam Língua Portuguesa, somente $54 \%$ tem formação na área específica, em Biologia, 50\%, em Matemática 38\%, em Educação Física, 36\%, em História, 34\%, em Química, 33\%, em Geografia, 29\% e em Física, 17\%. Considerando as regiões brasileiras, as maiores discrepâncias estão na região nordeste, e as menores discrepâncias estão na região sudeste. Isto nos sinaliza que temos muito que caminhar para prover as redes de ensino com docentes com formação em áreas específicas do currículo da educação básica. Soares (2015), tomando o conjunto de docentes atuando no ensino médio, e considerando a adequação acima apontada, nos mostra que, entre os que lecionam Sociologia, Artes e Filosofia, a média percentual de aderência formativa fica em $40 \%$.

$\mathrm{Na}$ tessitura dessas situações apresentadas toma sentido a complexidade que envolve a questão da formação de professores e a valorização de sua carreira e sua atratividade para os jovens. Coloca-nos, também, questões sobre a formação continuada que é oferecida nas redes de ensino. Assim, em resumo: temos atendimento quantitativo adequado nos primeiros anos do ensino fundamental, mas não na pré-escola, e temos grandes perdas na trajetória das crianças, adolescentes e jovens nas redes escolares, com aprendizagens que evidenciam grandes carências; as licenciaturas não suprem as necessidades das redes escolares em quantidade 
de licenciados, com diferenciais entre as áreas do conhecimento, o que leva a se ter professores improvisados em várias dessas áreas por falta de licenciados na disciplina; há grande evasão nos cursos de graduação - licenciatura, o que leva a considerar, embora não só, questões ligadas aos cursos e suas dinâmicas pedagógicas, e a questão de valorização desse curso nas instituições de ensino superior, bem como a atratividade da carreira; nos cursos de licenciatura em Pedagogia paira a indefinição - formar "pedagogo" ou o "professor de pré-escola e alfabetizador"? A questão é séria, pois, é esse o curso que por norma deve realizar essa formação. Ainda, temos pelas análises, um vácuo na formação de professores para a Educação Infantil, e análises que também nos apontam que representações vigentes nas licenciaturas mostram concepções formativas arraigadas em tradição cultural que se consolidou no início do século vinte e se mantém até hoje; encontram-se dificuldades nas graduações quanto ao reconhecimento dos diferenciais do exercício do magistério nos diferentes níveis de ensino e dificuldades com a ideia de que formar professor é formar um trabalhador profissional; enfim, verifica-se que as licenciaturas caracterizam-se por uma formação fragmentada, intra e inter cursos, com currículo fragilizado e estágios curriculares com problemas em sua realização efetiva, o que não contribui para a profissionalização docente e nem para a construção de uma identidade profissional e sua valorização. (Pretto e Lapa, 2010; Libâneo, 2010; Gatti, Silva Júnior, Pagotto e Nicoletti (org.), 2013; Monfredini, Maximiano e Lotfi, 2013; Gatti, 2014; Gatti, 2015; Barretto, 2015). A complexidade associada às políticas docentes está posta pela variada intersecção de fatores aí intervenientes.

Com as condições expostas pergunta-se: formam-se atualmente professores com condições de responder aos desafios da escola hoje, aos desafios de propiciar condições de aprendizagens efetivas aos alunos, nos contextos que caracterizam nossa sociedade e culturas? Isso nos reporta a ponderar sobre o que consideramos como qualidade na educação escolar. Não há como pensar a formação de professores para a educação básica sem levar em conta um cenário de qualificação para a educação nas escolas, refletindo e tendo no horizonte os propósitos para a educação básica. 


\section{Qualidade na educação escolar}

Primeiramente é preciso lembrarmos que educação implica ação entre pessoas, se a concebemos em seu sentido mais completo de formação humana e não apenas como processo que conduza apenas ao domínio intelectual de conteúdos. Desse modo, o fato educacional é cultural uma vez que a educação - enquanto pensamento, atuação e trabalho - está imersa na cultura, em estilos de vida, e não se acha apenas vinculada às ciências, aos conhecimentos já racionalizados, e, que o cerne do processo educacional é a formação das crianças, adolescentes e jovens - as novas gerações — que se constituem na história humana pelo entrelaçamento de processos cognitivos, afetivos, sociais, morais, dos conhecimentos e saberes, dos fazeres, do uso das técnicas ou de recursos diversos, da ação sobre as coisas e fatos do mundo. Não é um processo solitário, ele se faz na relação de adultos preparados com os mais novos, num processo que levou à institucionalização das escolas, e aqui, o papel do professor é central. Esse papel chama pelo domínio de um saber que alia conhecimento de conteúdos à didática e às condições de aprendizagem para segmentos diferenciados, associados a posturas éticas e estéticas. O processo educativo está, então, vocacionado à formação do pensamento e de valores e atitudes, quanto ao saber, ao sentido social dos saberes, às responsabilidades que temos uns com os outros, na compreensão de contextos variados, ambientais e culturais, constituindo um pensar que possa distinguir fatos e questões, com sentido crítico na direção de uma autonomia de escolhas. Aprendizagens específicas e gerais fazem parte desse processo.

Precisamos trazer constantemente à nossa consideração que conhecimento é um dos determinantes fortes de desigualdades sociais, é fator diferenciador de pessoas e grupos humanos, pois saber interpretar e formar juízos independentes é o pilar em que se assenta a construção de autonomia pessoal e das possibilidades de contrapontos que 
permitem superação de condições vivenciais desafiantes — na vida cotidiana, na atividade científica, no meio ambiente, nas condições societárias. Conhecimento aliado a uma consciência humanitária, de preservação da vida em condições dignas. O papel da educação se assenta nessas condições, e o trabalho nas redes escolares aí encontra seu sentido. O trabalho educacional escolar diz respeito a ações e intervenções, que são práticas culturais, as quais se ancoram em domínio de conhecimentos específicos em interface com conhecimentos didáticos, em formas de comunicação adequadas às etapas de desenvolvimento humano, ancorados em uma cultura geral, estabelecendo relações pedagógicas com sensibilidade cognitiva, tendo e favorecendo a construção de atitudes éticas. O que desponta no horizonte das demandas por equidade social e educacional, como discute Tedesco (2010), é que se possa construir uma escola justa que propicie a inclusão de todos e, não, exclusões e seletividades profundas, uma escola em que os estudantes aprendam, se eduquem e se qualifiquem para a vida como cidadãos. Para tanto, precisamos de professores que assumam esse compromisso em sua atuação na escola básica tendo condições formativas para leva-lo adiante. Para tal, as instituições formadoras de professores e seus gestores e docentes precisam estar conscientes da função social das escolas e, nelas, do papel dos professores, e também assumir esse compromisso por meio de seus processos formadores. Nessa direção as dinâmicas curriculares na formação de professores, nas graduações do ensino superior, precisam reinventar-se. Para isso é necessário ter consciência de que a formação oferecida não é suficiente ou adequada, fazer um exame profundo e objetivo de suas dinâmicas curriculares e ousar reinventar, inovar essas formações, tendo como foco a educação básica, destino de trabalho de profissionais docentes. Desenvolver iniciação à docência, para a educação básica, com a melhor qualidade, é compromisso ético e político com o desenvolvimento das novas gerações como cidadãos que possam exercer sua cidadania com autonomia e reflexões bem balizadas. 


\section{Complexidade e formação: professores e escolas}

Refletir sobre a formação de professores e construir caminhos que viabilizem a transformação do cenário atual das ações educacionais que se concretizam nas salas de aula na educação básica, demanda levar em conta a interação e a intersecção de múltiplas condições, intrínsecas a essa formação, considerando os novos movimentos societários que se mostram no mundo contemporâneo, com suas consequências, tendo no horizonte as lutas por dignidade social por parte de vários segmentos populacionais, e a meta de se conseguir equidade quanto ao usufruto de bens sociais e educacionais. Não se pode deixar de pensar e imprimir ações que, considerando os dados de nossa realidade educacional, possam de fato contribuir para a diminuição das desigualdades que estamos gerando com nosso sistema escolar. Nesse sentido, precisamos nos preocupar em garantir para as novas gerações aprendizagens efetivas e significativas. Escolas são o território e os professores são os agentes desse processo, lembrando que gestores escolares são formados inicialmente como professores e, em seu trabalho, o domínio dos conhecimentos sobre a função de ensinar do educando é essencial. Boa formação profissional, com consciência social, é do que estamos falando. Concluímos com Silva Júnior (2015, p. 133) que "Se, efetivamente, pretendemos revolucionar precisamos estar conscientes e convictos da exaustão histórica das formas de análise e dos processos de intervenção até aqui utilizados no tratamento da situação social que nos desafia, com sua inoperância e sua petrificação". O que leva esse autor a ponderar que "transformações radicais podem se operar em campos determinados da vida social, mas são frutos da ação organizada de pessoas e instituições que se propõem a alterar radicalmente situações dadas". Nesta linha de pensamento, para se conseguir nas instituições instauração de um novo modo de pensar a formação de docentes, definir melhor o valor e o papel dessa formação, há a necessidade de haver de um lado, consciência de que chegamos a uma situação totalmente insatisfatória nessa formação, e portanto insustentável, e, de outro, possibilidade de criação de alguma ação coletiva que permita trazer à tona contribuições 
fundantes originárias do campo das Teorias Pedagógicas e da Didática ao Conjunto de Áreas que são objeto dessa formação e da especialização de docentes. Considerando sempre que professores são profissionais da educação, com função social específica, o que pede por uma formação específica em adequação com o trabalho que irá realizar, formação essa aliada a perspectivas éticas com consciência das condições sociais na qual será inserida sua atuação.

\section{Referências}

BRASIL. Lei no 9.394, de 20 de dezembro de 1996. Diretrizes e Bases da Educação Nacional - LDB. Disponível em: http://portal.mec.gov.br/seed/arquivos/pdf/ tvescola /leis/lein9394.pdf. Acesso em 01 ago. 2016.

BRASIL. Presidência da República. Lei 12.796 de 04 de abril de 2013. Disponível em: http://www.planalto.gov.br/ccivil_03/_ato2011-2014/2013/lei/112796. htm. Acesso em 22 ago. 2016.

ALVES, T.; SILVA, R.M. Estratificação das oportunidades educacionais no Brasil: contextos e desafios para a oferta de ensino em condições de qualidade para todos. Educação e Sociedade, Campinas, SP, v. 34, n.124, p. 851 - 879, 2013.

AVALOS, B. (Ed.) Héroes o vilanos? La profesión docente em Chile. Santiago de Chile. Universitaria, 2013.

BARRETTO, E. S. S. Políticas de formação docente para educação básica no Brasil: embates e desafios. Revista Brasileira de Educação, Rio de Janeiro, v. 20, n. 62, p. 679-701, jul.-set. 2015.

CALLEGARI, C. Radicalizar o pacto pelas crianças do Brasil. IBSA-Instituto Brasileiro de Sociologia. Disponível em: http://www.ibsa.org.br/radicalizacao. php. Acesso em 09 set. 2015.

GATTI, B. A.; BARRETTO, E. S. S.; ANDRÉ, M. E. D. A. Políticas docentes no Brasil: um estado da arte. Brasília: UNESCO, 2011. 
GATTI, B. A. et al. Análises pedagógico-curriculares para os cursos de licenciatura vinculados às áreas de artes, biologia, história, língua portuguesa, matemática e pedagogia no âmbito da UAB e Parfor. Documento Técnico. Brasília: Unesco/Mec/ Capes, 2012.

GATTI, B. A. Formação inicial de professores para a educação básica: pesquisas e políticas educacionais. Estudos em Avaliação Educacional. v. 25, n. 57, p. 24 - 54, 2014.

GATTI, B. A. Políticas Educacionais e educação básica: desafios para as políticas e formação docente. In: Pacheco Rios, J. A. V. (Org.). Políticas, Práticas e Formação na Educação Básica. Salvador (BA): Editora da UFBA, 2015. p. 25 - 34.

GATTI, B. A.; SILVA JÚNIOR, A. C.; PAGOTTO, M. D. S.; NICOLETTI, M. G. Por uma política nacional de formação de professores. São Paulo: Editora Unesp, 2013.

LIBÂNEO, J. C. O ensino da Didática, das metodologias específicas e dos conteúdos específicos do ensino fundamental nos currículos dos cursos de Pedagogia. RBEP - Revista Brasileira de Estudos Pedagógicos. Brasília, v. 91, n. 229, p. 562583, 2010.

INEP. Resumos Técnicos - Censo da Educação Superior de 2009, 2010, 2011,2013. Disponível em: http://download.inep.gov.br/educacao_superior/censo_superior/resumo_tecnico/resumo_tecnico_cens. Acesso em 21/02/2015.

MEC/INEP/DEED. Indicadores Educacionais, 2013. Disponível em: http://portal. inep.gov.br/censo.indic. Acesso em 03/07/2015.

MONFREDINI, I.; MAXIMIANO, G. F.; LOTFI, M. C. (org) O deserto da formação inicial nas licenciaturas e alguns oásis. Jundiaí (SP): Paco Editorial, 2013.

PRETTO, N. de L.; LAPA, A. Educação a distância e precarização do trabalho docente. Em Aberto, Brasília, v. 23, n. 84, p. 79-97, nov. 2010.

RAMALHO, B. L.; NUÑEZ, I. B.; GAUTHIER, C. Formar o professor, profissionalizar o ensino. Porto Alegre: Editora Sulina, 2003. 
ROLDÃO, M. do C. Função docente: natureza e construção do conhecimento profissional. Revista Brasileira de Educação, n. 34, jan./abr. p. 94-103.

SILVA JÚNIOR, C. A. Construção de um espaço público de formação. In: Silva Júnior et al. Por uma revolução no campo da formação de professores. Editora Unesp, 2015. p. $133-148$.

SOARES, J. F. Desafios da Educação Básica Brasileira. INEP, nov. 2015. Seminário: Avaliação e gestão educacional em municípios brasileiros: mapeamento e caracterização das iniciativas em curso. Palestra de Abertura. P. P. Fundação Carlos Chagas, 13/11/2015.

TEDESCO, J. Presentación. In: OLIVEIRA, D. A. et al. Politicas educativas y territórios: modelos de articulación entre niveles de gobierno. IIPE/Unesco: Buenos Aires, 2010.

TODOS PELA EDUCAÇÃO. Microdados - Saeb/Inep: análises. Disponível em: http://www.todospelaeducacao.org.br/. Acesso em 06/03/2015.

Recebido: 08/09/2016

Received: 09/08/2016

Aprovado: 15/09/2016 Approved: 09/15/2016 
